\title{
RELASI EKUIVALEN LEMBUT DAN REDUKSI PARAMETER PADA HIMPUNAN LEMBUT
}

\author{
RAHMAT OGI SENTOSA, ADMI NAZRA, MONIKA RIANTI HELMI \\ Program Studi S1 Matematika, \\ Fakultas Matematika dan Ilmu Pengetahuan Alam, Universitas Andalas, \\ Kampus UNAND Limau Manis Padang, Indonesia. \\ email : rogisentosa@gmail.com,nazra@sci.unand.ac.id,monikariantihelmi@sci.unand.ac.id
}

Diterima 12 Juni 2021 Direvisi 22 Juni 2021 Dipublikasikan 26 Juli 2021

\begin{abstract}
Abstrak. Konsep himpunan lembut (soft sets) adalah sebuah metode yang digunakan untuk menyelesaikan suatu permasalahan pengambilan keputusan. Pada dasarnya konsep himpunan lembut memperhatikan cukup banyak parameter terkait. Namun ada kalanya tidak semua parameter tersebut dibutuhkan dalam pengambilan keputusan (dapat diabaikan/direduksi). Dalam membahas reduksi parameter pada himpunan lembut ini, akan digunakan konsep relasi ekuivalen, lebih khusus konsep relasi ekuivalen lembut. Dalam penelitian ini akan dikaji mengenai konsep relasi ekuivalen lembut dan beberapa sifat-sifat terkait. Kemudian akan dikaji juga tentang penerapan metode reduksi parameter pada himpunan lembut, dan mengonstruksi suatu algoritma dalam mengidentifikasi parameter yang dapat direduksi.
\end{abstract}

Kata Kunci: Himpunan Lembut, Reduksi Parameter, Relasi Ekuivalen Lembut

\section{Pendahuluan}

Konsep himpunan lembut (soft sets) adalah sebuah metode yang digunakan untuk menyelesaikan suatu permasalahan pengambilan keputusan. Salah satu penerapan konsep himpunan lembut adalah dibidang struktur aljabar yang diprakarsai oleh Aktas dan Cagman [1]. Dalam menentukan keputusan yang akan diambil pada konsep himpunan lembut, terdapat dua metode yaitu choice value dan weighted choice value yang diperkenalkan oleh Maji dan Roy [5].

Pada dasarnya konsep himpunan lembut memperhatikan cukup banyak parameter terkait. Namun ada kalanya tidak semua parameter tersebut dibutuhkan dalam pengambilan keputusan (dapat diabaikan/direduksi), dimana ada tidaknya parameter tersebut dalam pengambilan keputusan, keputusan akhirnya sama saja. Dalam membahas reduksi parameter pada himpunan lembut ini, akan digunakan konsep relasi ekuivalen, lebih khusus konsep relasi ekuivalen lembut. Sedangkan konsep relasi ekuivalen ini terdapat keterkaitan dengan konsep himpunan kasar.

${ }^{*}$ Penulis Korespondensi 
314 Rahmat Ogi Sentosa dkk.

Dalam artikel ini akan dikaji kembali konsep tentang relasi ekuivalen lembut dan beberapa sifat-sifat terkait. Kemudian akan dikaji juga tentang penerapan metode reduksi parameter pada himpunan lembut, dan mengonstruksi suatu algoritma dalam mengidentifikasi parameter yang dapat direduksi yang merupakan kajian kembali dari artikel Muhammad Irfan Ali [3].

\section{Landasan Teori}

\subsection{Relasi Ekuivalen}

Misalkan $U$ adalah himpunan tak kosong yang disebut himpunan semesta dan setiap subhimpunan $U \times U$ disebut relasi biner pada $U$. Jika $R$ adalah relasi biner pada $U$ maka $R$ disebut:

(a) refleksif, jika $(x, x) \in R$ untuk setiap $x \in U$;

(b) simetris, jika $(x, y) \in R$ maka $(y, x) \in R$ untuk setiap $x, y \in U$; dan

(c) transitif, jika $(x, y) \in R$ dan $(y, z) \in R$ maka $(x, z) \in R$ untuk setiap $x, y, z \in U$.

Suatu relasi biner $R$ disebut relasi ekuivalen jika $R$ adalah refleksif, simetris, dan transitif.

Definisi 2.1. [7] Suatu sistem representasi parameter adalah suatu pasangan $K=$ $(U, A)$ dimana $U$ adalah suatu himpunan semesta tak kosong dan $A$ adalah suatu himpunan parameter yang tidak kosong.

Definisi 2.2. [7] Misalkan $U$ suatu himpunan semesta dan $\boldsymbol{R}$ adalah suatu koleksi dari relasi-relasi ekuivalen pada $U$. Pasangan $K=(U, \boldsymbol{R})$ disebut suatu sistem relasi.

Definisi 2.3. [7] Misalkan A suatu himpunan parameter. Untuk setiap $B \subseteq A$, relasi ekuivalen yang bersesuaian dengan $B$ yang disimbolkan $I N D(B)$ disebut relasi indiscernibility, yang didefinisikan sebagai

$$
\begin{aligned}
I N D(B) & =\bigcap_{\beta \in B} I N D(\beta) \\
& =\{(x, y) \in U \times U \mid \forall \beta \in B, \beta(x)=\beta(y)\}, \text { dengan } \\
I N D(\beta) & =\{(x, y) \in U \times U \mid \beta(x)=\beta(y)\} .
\end{aligned}
$$

Definisi 2.4. [3] Misalkan $\boldsymbol{R}$ suatu koleksi dari relasi-relasi ekuivalen, maka untuk suatu $\alpha \in \boldsymbol{R}$,

(a) $\alpha$ disebut dapat direduksi (dispensable) jika $\operatorname{IND}(\boldsymbol{R})=\operatorname{IND}(\boldsymbol{R}-\{\alpha\})$,

(b) $\alpha$ disebut tidak dapat direduksi (indispensable) jika $I N D(\boldsymbol{R}) \neq I N D(\boldsymbol{R}-$ $\{\alpha\})$.

Definisi 2.5. [7] Misalkan $K=(U, A)$ merupakan suatu sistem representasi parameter dan $B, C \subseteq A$ maka: 
(1) himpunan parameter $C$ dikatakan bergantung pada himpunan parameter $B$ yang dilambangkan dengan $B \Rightarrow C$ jika dan hanya jika $\operatorname{IND}(B) \subseteq$ $I N D(C)$;

(2) himpunan parameter $C$ dikatakan ekuivalen dengan himpunan parameter $B$ yang dilambangkan dengan $C \cong B$ jika dan hanya jika $C \Rightarrow B$ dan $B \Rightarrow C$; dan

(3) himpunan parameter $C$ dikatakan bebas (tidak bergantung) dengan $B$ yang dilambangkan dengan $C \neq B$, jika dan hanya jika tidak berlaku $C \Rightarrow B$ maupun $B \Rightarrow C$.

\subsection{Himpunan Lembut}

Definisi 2.6. [6] Misalkan $U$ adalah suatu himpunan semesta (himpunan objekobjek) dan E adalah suatu himpunan parameter. Pasangan $(F, E)$ disebut himpunan lembut atas $U$ jika dan hanya jika $F$ adalah pemetaan dari himpunan $E$ ke himpunan dari semua subhimpunan dari $U, F: E \rightarrow P(U)$, dimana $P(U)$ adalah himpunan kuasa dari $U$.

Definisi 2.7. [4] Misalkan $(F, A)$ dan $(G, B)$ adalah himpunan lembut atas $U$, definisikan $(F, A)$ adalah himpunan bagian lembut dari $(G, B)$ ditulis dengan $(F, A) \subseteq(G, B) j i k a$

(1) $A \subseteq B$, dan

(2) $F(e) \subseteq G(e)$ untuk setiap $e \in A$

Definisi 2.8. [4] Misalkan $(F, A)$ dan $(G, B)$ himpunan lembut atas $U,(F, A)$ sama lembut dengan $(G, B)$ jika dan hanya jika $(F, A)$ adalah himpunan bagian lembut dari $(G, B)$ dan $(G, B)$ adalah himpunan bagian lembut dari $(F, A)$.

Definisi 2.9. [2] Misalkan $U$ adalah suatu himpunan semesta, dan E adalah suatu himpunan parameter. Untuk suatu $A \subseteq E$,

(a) $(F, A)$ disebut himpunan null relatif lembut atas $U$ yang dilambangkan dengan $\emptyset_{A}$, jika $F(a)=\emptyset$ untuk setiap $a \in A$,

(b) $(G, A)$ disebut himpunan penuh relatif lembut atas $U$ yang dilambangkan dengan AU, jika $G(e)=U$ untuk setiap $e \in A$.

Definisi 2.10. [2] Misalkan $(F, A)$ dan $(G, B)$ adalah dua buah himpunan lembut atas $U$ maka:

(1) gabungan diperluas dari $(F, A)$ dan $(G, B)$, didefinisikan sebagai $(H, C):=(F, A) \cup_{\varepsilon}(G, B)$, dimana $(H, C)$ adalah himpunan lembut atas $U$ dengan $C=A \cup B$, dan untuk setiap $e \in C$, berlaku

$$
H(e)=\left\{\begin{array}{lr}
F(e) & \text { jika } e \in A-B, \\
G(e) & \text { jika } e \in B-A, \\
F(e) \cup G(e) & \text { jika } e \in A \cap B,
\end{array}\right.
$$


(2) gabungan terbatas dari $(F, A)$ dan $(G, B)$ didefinisikan sebagai $(H, D):=(F, A) \cup_{\mathcal{R}}(G, B)$, dimana $(H, D)$ adalah himpunan lembut atas $U$ dengan $D=A \cap B \neq \emptyset$, dan untuk setiap $e \in D$ berlaku $H(e)=F(e) \cup G(e)$, sedangkan jika $A \cap B=\emptyset$, maka $(F, A) \cup_{\mathcal{R}}(G, B)=\emptyset_{\emptyset}$.

Definisi 2.11. [2] Misalkan $(F, A)$ dan $(G, B)$ adalah himpunan lembut atas $U$ maka:

(1) irisan diperluas dari $(F, A)$ dan $(G, B)$ didefinisikan sebagai $(H, C):=(F, A) \cap_{\varepsilon}(G, B)$, dimana $(H, C)$ himpunan lembut atas $U$ dengan $C=A \cup B$, dan untuk setiap $e \in C$, berlaku

$$
H(e)=\left\{\begin{array}{lr}
F(e) & \text { jika } e \in A-B, \\
G(e) & \text { jika } e \in B-A, \\
F(e) \cap G(e) & \text { jika } e \in A \cap B,
\end{array}\right.
$$

(2) irisan terbatas dari $(F, A)$ dan $(G, B)$ didefinisikan sebagai $(H, D):=(F, A) \cap_{\mathcal{R}}(G, B)$, dimana $(H, D)$ adalah himpunan lembut atas $U$ dengan $D=A \cap B \neq \emptyset$, dan untuk setiap $e \in D$ berlaku $H(e)=F(e) \cap G(e)$, sedangkan jika $A \cap B=\emptyset$, maka $(F, A) \cap_{\mathcal{R}}(G, B)=\emptyset_{\emptyset}$.

Definisi 2.12. [2] Misalkan (F,A) himpunan lembut atas $U$. Komplemen relatif dari $(F, A)$ ditulis dengan $(F, A)^{r}$ yang didefinisikan sebagai $\left(F^{r}, A\right)$ dimana $F^{r}: A \rightarrow P(U)$ dengan $F^{r}(a)=U-F(a)$ untuk setiap $a \in A$.

\subsection{Himpunan Kasar}

Misal diberikan $U$ adalah suatu himpunan semesta tak kosong, dan $R$ adalah suatu relasi ekuivalen pada $U$. Pasangan $(U, R)$ disebut juga sebagai ruang hampiran. Jika $X$ subhimpunan dari $U$, maka $X$ dapat ditulis sebagai gabungan beberapa kelaskelas ekuivalen pada $U$. Jika $X$ dapat ditulis sebagai gabungan beberapa kelas-kelas ekuivalen pada $U$, maka $X$ disebut terdefinisi, dan jika tidak, maka $X$ disebut tidak terdefinisi. Jika $X$ adalah suatu subhimpunan yang tidak terdefinisi maka $X$ dapat dihampiri dengan dua subhimpunan yang terdefinisi yang disebut hampiran bawah dan hampiran atas dari $X$ yang didefinisikan sebagai berikut

(a) hampiran bawah dari $X$ didefinisikan dengan

$$
\underline{\operatorname{app}}(X)=\bigcup\left\{[x]_{\mathcal{R}} \quad \text { dimana } \quad[x]_{\mathcal{R}} \subseteq X, x \in U\right\} ; \text { dan }
$$

(b) hampiran atas dari $X$ didefinisikan dengan

$$
\overline{\operatorname{app}}(X)=\bigcup\left\{[x]_{\mathcal{R}} \quad \text { dimana } \quad[x]_{\mathcal{R}} \cap X \neq \emptyset, x \in U\right\} ;
$$

dengan $[x]_{\mathcal{R}}$ adalah suatu kelas ekuivalen yang bersesuain dengan $x$ pada relasi ekuivalen $R$ [3].

Definisi 2.13. [3] Misalkan $U$ adalah suatu himpunan semesta dan $X \subseteq U$, dan $\operatorname{app}(X)$ dan $\overline{a p p}(X)$ masing-masing adalah hampiran bawah dan hampiran 
atas dari $X$. Himpunan kasar dari $X$ didefinisikan sebagai pasangan terurut $(\underline{\operatorname{app}}(X), \overline{\operatorname{app}}(X))$.

Himpunan $\overline{a p p}(X)-\operatorname{app}(X)$ disebut wilayah batas, sedangkan himpunan $\underline{\operatorname{app}}(X)-\overline{\operatorname{app}}(X)$ adalah himpunan kosong. Jika $\underline{\operatorname{app}}(X)=\overline{\operatorname{app}}(X)$ maka $X$ disebut terdefinisi.

\section{Relasi Ekuivalen Lembut}

Definisi 3.1. [3] Misalkan U suatu himpunan semesta tak kosong dan A suatu himpunan parameter. Didefinisikan suatu pemetaan $\sigma$ dari himpunan parameter $A$ ke himpunan kuasa atas $U \times U, \sigma: A \rightarrow P(U \times U)$. Himpunan lembut $(\sigma, A)$ atas $(U \times U)$ disebut relasi biner lembut pada $U$. Dalam hal ini, $(\sigma, A)$ disebut juga sebagai koleksi berparameter dari relasi-relasi biner pada $U$.

Definisi 3.2. [3] Misalkan $(\sigma, A)$ dan $(\rho, B)$ adalah dua relasi biner lembut pada $U$. Komposisi dari $(\sigma, A)$ dan $(\rho, B)$ dilambangkan dengan $(\sigma, A) \odot(\rho, B)$ yang didefinisikan sebagai $(\delta, C):=(\sigma, A) \odot(\rho, B)$ dimana $C=A \times B$ dan $\delta(a, b)=\sigma(a) \circ \rho(b)$ untuk $a \in A, b \in B$. Dalam hal ini $\sigma(a) \circ \rho(b)$ didefinisikan sebagai

$$
\sigma(a) \circ \rho(b)=\{(x, y) \in U \times U ; \exists z \in U, \ni(x, z) \in \sigma(a) \text { dan }(z, y) \in \rho(b)\} .
$$

Definisi 3.3. [3] Misalkan $(\sigma, A)$ dan $(\rho, B)$ adalah dua relasi biner lembut pada $U$. Komposisi terbatas dari $(\sigma, A)$ dan $(\rho, B)$ dilambangkan dengan $(\sigma, A) \circ_{\mathcal{R}}(\rho, B)$ yang didefinisikan sebagai $(\delta, D):=(\sigma, A) \circ_{\mathcal{R}}(\rho, B)$ dimana $D=A \cap B \neq \emptyset$ dan $\delta(d)=\sigma(d) \circ \rho(d)$ untuk $d \in D$. Dalam hal ini $\sigma(d) \circ \rho(d)$ didefinisikan sebagai

$$
\sigma(d) \circ \rho(d)=\{(x, y) \in U \times U ; \exists z \in U, \ni(x, z) \in \sigma(d) \text { dan }(z, y) \in \rho(d)\} .
$$

Jika $A \cap B=\emptyset$ maka komposisi terbatas $(\sigma, A) \circ_{\mathcal{R}}(\rho, B)=\emptyset_{\emptyset}$.

Definisi 3.4. [3] Misalkan $(\sigma, A)$ adalah suatu relasi biner lembut pada $U$. Didefinisikan suatu invers dari relasi biner lembut $(\sigma, A)$ yang dilambangkan dengan $(\sigma, A)^{-1}$ dengan definisi sebagai $(\sigma, A)^{-1}=\left\{\sigma^{-1}(a) ; a \in A\right\}$ dimana $\sigma^{-1}(a)=\{(y, x) ;(x, y) \in \sigma(a)\}$. Dalam hal ini $(\sigma, A)^{-1}$ juga merupakan koleksi berparameter.

Definisi 3.5. [3] Misalkan $(\sigma, A)$ adalah suatu relasi biner lembut pada $U$. $(\sigma, A)$ disebut relasi ekuivalen lembut atas $U$ jika $\sigma(a) \neq \emptyset$ dan $\sigma(a)$ adalah suatu relasi ekuivalen pada $U$ untuk setiap $a \in A$.

Berdasarkan kelas-kelas ekuivalen yang memuat $x \in U$, dapat dibentuk suatu hampiran bawah dan hampiran atas seperti pada himpunan kasar. Koleksi berparameter dari relasi-relasi biner pada subhimpunan $X \subseteq U$ yang ditulis dengan $\left(\underline{\sigma}^{X}, A\right)$, didefinisikan sebagai

$$
\underline{\sigma}^{X}(a)=\bigcup_{x \in X}\left\{[x]_{\sigma(a)} \quad \text { dimana } \quad[x]_{\sigma(a)} \subseteq X, a \in A\right\} .
$$

Pasangan $\left(\underline{\sigma}^{X}, A\right)$ disebut sebagai hampiran lembut bawah dari $X$ yang berkaitan dengan relasi ekuivalen lembut $(\sigma, A)$. Koleksi berparameter dari relasi-relasi biner pada subhimpunan $X \subseteq U$ yang ditulis dengan $\left(\bar{\sigma}^{X}, A\right)$, didefinisikan sebagai 


$$
\bar{\sigma}^{X}(a)=\bigcup_{x \in X}\left\{[x]_{\sigma(a)} \quad \text { dimana } \quad[x]_{\sigma(a)} \cap X \neq \emptyset, a \in A\right\} .
$$

Pasangan $\left(\bar{\sigma}^{X}, A\right)$ disebut sebagai hampiran lembut atas dari $X$ yang berkaitan dengan relasi ekuivalen lembut $(\sigma, A)$.

Hampiran lembut bawah dan hampiran lembut atas dari $X$ juga bisa dibentuk menjadi suatu himpunan lembut baru yang dilambangkan $\left(B \sigma^{X}, A\right)$ dengan definisi $B \sigma^{X}(a)=\bar{\sigma}^{X}(a)-\underline{\sigma}^{X}(a)$ untuk setiap $a \in A$. Himpunan lembut $\left(B \sigma^{X}, A\right)$ disebut dengan wilayah lembut batas dari $X$ yang berkaitan dengan relasi ekuivalen lembut $(\sigma, A)$. Berdasarkan wilayah lembut batas dari $X$ yang berkaitan dengan $(\sigma, A)$, subhimpunan $X$ dari $U$ dapat dikelompokkan menjadi tiga yaitu:

(1) subhimpunan $X$ disebut kasar total, jika $B \sigma^{x}(a) \neq \emptyset$ untuk setiap $a \in A$,

(2) subhimpunan $X$ disebut kasar sebagian atau terdefinisi sebagian, jika $B \sigma^{x}(a)=\emptyset$ untuk beberapa $a \in A$, tetapi tidak untuk setiap $a \in A$,

(3) subhimpunan $X$ disebut terdefinisi, jika $B \sigma^{x}(a)=\emptyset$ untuk setiap $a \in A$.

Proposisi 3.6. [3] Jika $(\sigma, A)$ dan $(\rho, B)$ adalah relasi ekuivalensi lembut pada $U$ maka:

(1) $(\sigma, A) \cap_{\mathcal{R}}(\rho, B)$, dan

(2) $(\sigma, A) \cap_{\varepsilon}(\rho, B)$,

adalah relasi ekuivalensi lembut atas $U$.

Proposisi 3.7. [3] Misalkan $U$ suatu himpunan semesta tak kosong dan $X, Y \subset U$. Untuk setiap relasi ekuivalensi lembut $(\sigma, A)$ pada $U$ berlaku:

(1) $\left(\underline{\sigma}^{X}, A\right) \subseteq\left(\bar{\sigma}^{X}, A\right)$,

(2) $\left(\underline{\sigma}^{\emptyset}, A\right)=\left(\bar{\sigma}^{\emptyset}, A\right)=\emptyset_{A} ;\left(\underline{\sigma}^{U}, A\right)=\left(\bar{\sigma}^{U}, A\right)=A \mathfrak{U}$,

(3) $\left(\bar{\sigma}^{X \cup Y}, A\right)=\left(\bar{\sigma}^{X}, A\right) \cup_{\mathcal{R}}\left(\bar{\sigma}^{Y}, A\right)$,

(4) $\left(\underline{\sigma}^{X \cap Y}, A\right)=\left(\underline{\sigma}^{X}, A\right) \cap_{\mathcal{R}}\left(\underline{\sigma}^{Y}, A\right)$,

(5) $X \subseteq Y, \operatorname{maka}\left(\underline{\sigma}^{X}, A\right) \subseteq\left(\underline{\sigma}^{Y}, A\right)$,

(6) $X \subseteq Y$, maka $\left(\bar{\sigma}^{X}, A\right) \subseteq\left(\bar{\sigma}^{Y}, A\right)$,

(7) $\left(\underline{\sigma}^{X \cup Y}, A\right) \supseteq\left(\underline{\sigma}^{X}, A\right) \cup \cup_{\mathcal{R}}\left(\underline{\sigma}^{Y}, A\right)$,

(8) $\left(\bar{\sigma}^{X \cap Y}, A\right) \subseteq\left(\bar{\sigma}^{X}, A\right) \cap_{\mathcal{R}}\left(\bar{\sigma}^{Y}, A\right)$,

(9) $\left(\underline{\sigma}^{X^{c}}, A\right) \subseteq\left(\left(\bar{\sigma}^{X}\right), A\right)^{r}$.

\section{Reduksi Parameter pada Himpunan Lembut dan Aplikasinya}

\subsection{Reduksi Parameter}

Definisi 4.1. [3] Misalkan $T=(U, A, C, D)$ adalah tabel keputusan yang konsisten dan $T_{\gamma}=\left(U, A, C-\gamma, D_{\gamma}\right)$ adalah tabel keputusan yang mana kolom-kolom $\gamma$ dikeluarkan dari $C$. Kolom-kolom $\gamma$ dari $C$ disebut dapat direduksi di $T$ jika:

(1) $T_{\gamma}$ konstisten; dan

(2) $I N D(D)=I N D\left(D_{\gamma}\right)$.

Definisi 4.2. [3] Misalkan $\alpha$ dan $\beta$ dua parameter, dimana $\alpha \neq \beta$. Parameter $\alpha$ dan $\beta$ disebut pengklasifikasi ekuivalen jika $[x]_{\alpha}=[x]_{\beta}$ untuk setiap 
$x \in U$, dimana $[x]_{\alpha}$ menyatakan kelas ekuivalen dari $x$ yang terkait dengan relasi ekuivalen $\alpha$.

Proposisi 4.3. [3] Misalkan $T=(U, A, C, D)$ dan $T_{\gamma}=\left(U, A, C-\gamma, D_{\gamma}\right)$ adalah tabel-tabel keputusan yang konsisten. Himpunan parameter kondisi $\gamma$ dapat direduksi jika dan hanya jika $D$ dan $D_{\gamma}$ adalah pengklasifikasi ekuivalen.

\subsection{Aplikasi Pada Masalah Pengambilan Keputusan dari Reduksi Parameter}

Algoritma untuk menentukan parameter yang dapat direduksi pada himpunan lembut, yang tidak mengubah hasil keputusan yang diambil.

(1) menentukan himpunan lembut $(F, E)$;

(2) menentukan parameter kondisi $C \subseteq E$;

(3) menentukan parameter keputusan $D$ dengan $d_{i}=\sum_{\forall j} h_{i j}$, dimana $h_{i j}$ adalah entri yang ada pada baris $i$ dan kolom $j$ di tabel keputusan $T$;

(4) mengurutkan penempatan objek-objek $U$ sesuai dengan nilai dari parameter $D$;

(5) mengidentifikasi parameter yang dapat direduksi dan tidak dapat direduksi berdasarkan Definisi 4.1 atau Proposisi 4.3; dan

(6) menuliskan kembali tabel keputusan yang telah mereduksi semua parameter yang dapat diabaikan, sehingga menghasilkan tabel keputusan dengan jumlah parameter kondisi minimun.

\section{Kesimpulan}

Konsep relasi ekuivalen dapat diterapkan pada himpunan lembut yang disebut dengan relasi ekuivalen lembut. Dari definisi relasi ekuivalen lembut dapat diturunkan sifat-sifat yang terkait dengan kelas-kelas ekuivalen. Konsep relasi ekuivalen lembut menjadi dasar dalam merumuskan parameter-parameter yang dapat direduksi, dimana suatu parameter dapat direduksi jika dan hanya jika kelas ekuivalen pada himpunan parameter keputusan dari tabel keputusan sebelum dan sesudah direduksi adalah sama. Algoritma untuk menentukan parameter-parameter yang dapat direduksi yaitu: terlebih dahulu menentukan himpunan lembut, parameter kondisi dan parameter keputusan, selanjutnya mengurutkan penempatan objekobjek, lalu mengidentifikasi parameter yang dapat direduksi, terakhir menuliskan kembali tabel keputusan yang telah mereduksi semua parameter yang dapat diabaikan.

\section{Ucapan Terima kasih}

Penulis mengucapkan terima kasih kepada Ibu Yanita, Ibu Haripamyu, dan Ibu Hazmira Yozza yang telah memberikan masukan dan saran sehingga artikel ini dapat diselesaikan dengan baik. 
320 Rahmat Ogi Sentosa dkk.

\section{Daftar Pustaka}

[1] Aktas, H. dan Cagman, N. 2007. Soft set and Soft Groups. Information Sciences. 177: 2726-2735

[2] Ali, M. I., Feng F., Liu X. Y., Min W. K., dan Shabir, M. 2009. On some new operations in soft set theory. Computers and Mathematics with Applications. 57: $1547-1553$

[3] Ali, M. I. 2012. Another view on reduction of parameters in soft sets. Applied Soft Computing. 12: 1814-1821

[4] Maji, P. K., Biswas, R., Roy, R. 2013. Soft set theory. Computers and Mathematics with Applications. 45: 555-562

[5] Maji, P. K. dan A.R. Roy. 2002. An Application of Soft Sets in A Decision Making Problem. Computers and Mathematics with Applications. 44: 1077-1083

[6] Molodtsov, D. 1999. Soft set theory first result. Computers and Mathematics with Applications. 37: 19-31

[7] Pawlak, Z. 1991. Rough sets. Theoretical Aspects of Reasoning About Data. Kluwer Academic Publishers, Netherlands

[8] Rao, G. Shanker. 2009. Discrete Mathematical Structures, Second Edition. New Age International Publishers, New Delhi 